\title{
Analisis Penerapan Akad Mudharabah Pada Pemberian Modal Pakan Ikan Berdasarkan Kajian Ekonomi Syari'ah
}

\author{
Dani Ahmad ${ }^{1}$, Moch. Cahyo Sucipto ${ }^{2}$, Rina Nurhayati ${ }^{3}$ \\ ${ }^{1}$ STAI Riyadhul Jannah Subang \\ ${ }^{23}$ STIES Indonesia Purwakarta \\ ${ }^{1}$ daniiahmadd1@gmail.com \\ 2cahyosucipto@gmail.com \\ 3inamaza212@gmail.com
}

\begin{abstract}
Abstrak-Artikel ini membahas tentang Analisis Penerapan Akad Mudharabah Pada Pemberian Modal Pakan Ikan Berdasarkan Kajian Ekonomi Syari'ah. Akad Mudharabah adalah Salah satu bentuk kerjasama dalam menggerakkan antara pemilik modal dengan seseorang yang disebut bagi hasil, yang dilandasi oleh rasa tolong menolong dan asas kepercayaan diantara keduanya. Sebab ada orang yang mempunyai modal, tetapi tidak mempunyai keahlian dalam menjalankan roda perusahaan. Tujuan dari penelitian ini adalah untuk mengetahui mekanisme pemberian modal pakan ikan di PD. Bangun Jaya Fish Farm dan untuk mengetahui Tinjauan Ekonomi Syari'ah pada Pemberian Modal Pakan Ikan di PD. Bangun Jaya Fish Farm. Metode penelitian yang digunakan adalah metode deskriptif kualitatif yaitu penelitian yang menggambarkan serta menyajikan suatu peristiwa yang terjadi di lapangan dengan menggunakan teknik pengumpulan tringulasi data yaitu melalui observasi, wawancara, dokumentasi, dan juga penelitian kepustakaan dengan membaca buku, jurnal, artikel, website yang berkaitan dengan masalah yang akan diteliti. Hasil dari penelitian ini adalah bahwa mekanisme yang dilakukan dalam praktek pemberian modal pakan ikan dalam mekanismenya dijelaskan bahwa kerjasama antara pemilik modal dan pengelola modal tersebut yaitu akad mudharabah. Jika ditinjau berdasarkan Fatwa Dewan Syariah Nasional nomor: 115/DSNMUI/IX/2017 tentang akad mudharabah bahwa pemberian modal pakan ikan ini sudah termasuk kedalam akad mudharabah dan sah (diperbolehkan). Dalam perjanjian pengelola tidak boleh menjual ikan yang siap panen kepada pihak lain. Akan tetapi, oknum pengelola yang bekerjasama dengan PD. Bangun Jaya Fish Farm melanggar perjanjiannya yaitu ikan yang siap panen tersebut dijual kepada pihak lain.
\end{abstract}

Kata Kunci - Akad Mudharabah, Pemberian Modal Pakan Ikan.

\begin{abstract}
Analysis of the Application of Mudharabah Covenants in Fish Feed Capital Based on Sharia Economic Studies. Mudharabah agreement is a form of cooperation in moving between the owner of capital with someone called profit sharing, which is based on a sense of help and the principle of trust between the two. Because there are people who have capital, but do not have expertise in running a company. The research method used is descriptive qualitative method that is research that describes and presents an event that occurs in the field using data collection techniques that are through observation, interviews, documentation, and also library research by reading books, journals, articles, websites related to the problem to be examined. The results of this study are that the mechanism carried out in the practice of providing fish feed capital in the mechanism explained that the collaboration between the capital owner and the capital manager is mudharabah contract. If it is reviewed based on the Fatwa National Sharia Council number: 115/DSN-MUI /IX/2017 concerning mudharabah agreements that the provision of fish feed capital is included in the mudharabah agreements and is legal (allowed). In the agreement the manager may not sell fish that are ready to harvest to other parties. However, that management guy is cooperating with PD. Bangun Jaya Fish Farm that is those harvesting fish are sold to others.
\end{abstract}

Keywords - Mudharabah Agreement, Fish Feed Capital Provision. 


\section{Pendahuluan}

Manusia merupakan makhluk sosial, makhluk yang berkodrat hidup dalam bermasyarakat. Sebagai makhluk sosial manusia membutuhkan manusia yang lain. Manusia bersama-sama hidup dalam masyarakat dan disadari atau tidak, mereka saling berhubungan satu sama lain, untuk memenuhi kebutuhan hidupnya. Pergaulan hidup antar manusia dalam rangka untuk memenuhi kebutuhan hidupnya tersebut yang dinamakan muamalah. ${ }^{1}$

Pada kegiatan muamalah pakan ikan merupakan salah satu komponen yang sangat menunjang kegiatan usaha budidaya perikanan, sehingga pakan yang tersedia harus memadai dan memenuhi kebutuhan ikan. Pada budidaya ikan 60\%-70\% biaya produksi digunakan untuk biaya pakan. Kualitas pakan itu sendiri sangat diperhatikan dan dibutuhkan untuk mengefisiensikan pertumbuhan ikan itu sendiri dalam memenuhi kebutuhan pasar. Di jaman sekarang ini bahan pokok pakan sangat mahal dikarenakan sebagian bahan pokok pakan diperoleh dari import. Oleh karena itu segi biaya pakan merupakan faktor yang paling tinggi pengeluarannya. Ketersediaan pakan akan mempengaruhi kelangsungan dan pertumbuhan ikan itu sendiri, Karena ketersediaan pakan akan berpengaruh terhadap pertumbuhan dan kelangsungan hidup ikan yang dibudidayakan. ${ }^{2}$

Terkait dalam muamalah, kegiatan usaha perikanan merupakan sumber penghasilan bagi masyarakat di Cijambe. Kebanyakan dari pengusaha-pengusaha kecil menengah kebawah sehingga menyangkut permodalan menjadi penyebab utama dalam budidaya ikan di Desa Cijambe. Sumber daya alam di desa Cijambe sangatlah kaya dan subur, terutama dalam sumber pengairanya. Sehingga banyak masyarakat memanfaatkan sumber pengairan tersebut untuk membangun sebuah usaha budidaya ikan kolam air deras. Pakan menjadi masalah utama dalam melakukan kegiatan usaha kolam air deras, dikarenakan bahan pokok pakan mengalami kenaikan harga yang signifikan dan berpengaruh pada harga pakan yang akan di pasarkan. $^{3}$

\footnotetext{
${ }^{1}$ Syarafuddin dkk, Studi Islam 2, Surakarta: Lembaga Pengembangan Ilmu-Ilmu Dasar Bidang Studi Islam dan Kemuhammadiyahan UMS, 2006, 137.

2 Afrianto dan Liviawaty, Jurnal Vita Yanuar, (Universitas Antakusuma, 2017).

3 Hasil wawancara, Bapak Aep, Pembubidaya ikan kolam air deras, pada tanggal 03 Agustus 2019
}

Dalam penelitian ini saya melihat dan mengamati bahwa para pengusaha ikan di Desa Cijambe dan sekitarnya merasa terbebani dalam pembelian pakan ikan yang bisa dikatakan mahal. Hal ini sebagaimana dijelaskan oleh salah seorang pembudidaya ikan yang bernama Bapak Aep. ${ }^{4}$ Pakan ikan kami diformulasikan dan diproduksi dengan mengikuti spesifikasi kebutuhan nutrisi untuk setiap tipe ikan dan tahapan pertumbuhannya. Industri akuakultur merupakan komponen penting bagi perikanan Indonesia yang berkontribusi terhadap keamanan pangan nasional, pendapatan dan penyerapan tenaga kerja. Saat ini, perkembangan industri akuakultur Indonesia telah berkembang pesat dan dinilai penting dalam mendukung perkembangan ekonomi daerah.

Ikan yang dibudidayakan, yaitu mengkonsumsi pakan buatan yang diformulasikan secara khusus untuk memenuhi kebutuhan nutrisi esensial yang dibutuhkan oleh Ikan agar tetap sehat dan bertumbuh dengan optimal, serta memperhatikan kesehatan manusia sebagai konsumen dari Ikan dan Udang tersebut. Ada banyak gizi (nutrient) dan asam amino esensial yang diperlukan agar pertumbuhan Ikan dapat optimum, yang tersedia oleh sejumlah bahan pakan termasuk ikan, tanaman, dan olahan daging dalam bentuk tepung, serta minyak ikan dan nabati, karenanya semua bahan baku diproses dengan teknologi tinggi untuk mempertahankan nutrient dan asam amino yang terkandung, sejak dari bahan baku sampai dengan terbentuk menjadi pellet atau lainnya sesuai dengan spesies.

Pakan pada umumnya dibuat bentuk pellet dengan dua sifat, ada yang terapung (floating) dan ada yang tenggelam (sinking). Pakan terapung yang berbentuk bulat dan pakan tenggelam yang berbentuk memanjang dari kedua pakan tersebut sama-sama mempunyai nilai gizi sesuai dengan kebutuhan ikan. Selain dari pada sifatnya, pakan dibuat dengan nutrient dan ukuran bervariasi sesuai dengan umur dan kebutuhan untuk pertumbuhannya yang optimum. Karenanya jika pakan dengan nutrient yang tidak memadai, kenaikan berat badan akan lambat karena kebutuhan nutrient mereka tidak terpenuhi. Jika pembuatan pakan dengan nutrient yang berlebihan dapat mengakibatkan ikan yang mengkonsumsi pakan tersebut menjadi menurun

4 Hasil wawancara, Bapak Aep, Pembubidaya ikan kolam air deras, pada tanggal 03 Agustus 2019 


\section{EKSISBANK Vol. 3 No. 2 Desember 2019}

dan berat badan berkurang. Karenanya kami mengerti, begitu besar peranan Pakan Pabrikan dalam pembangunan Perikanan Budidaya di Indonesia, untuk mencapai hasil yang optimal, dengan formulasi dan teknologi yang handal, terpercaya.

Produsen pakan yang ada di Indonesia sudah sangat berkontribusi dalam pembangunan dan pembuatan pakan ikan dan ikut serta membangun perekonomian yang ada di Indonesia, dengan standar terbaik, serta memperhatikan kesehatan manusia sebagai konsumen akhir dari hasil budidaya nya.

Mudharabah adalah salah satu bentuk kerjasama dalam menggerakkan antara pemilik modal dengan seseorang yang disebut bagi hasil, yang dilandasi oleh rasa tolong menolong. Sebab ada orang yang mempunyai modal, tetapi tidak mempunyai keahlian dalam menjalankan roda perusahaan. Ada juga orang yang mempunyai modal dan keahlian, tetapi tidak mempunyai waktu. Sebaliknya ada orang yang mempunyai keahlian dan waktu, tetapi tidak mempunyai modal. Dengan demikian, apabila ada kerjasama dalam menggerakkan roda perekonomian, maka kedua belah pihak akan mendapatkan keuntungan modal dan skill (keahlian) dipadukan menjadi satu. ${ }^{5}$

Maksud penulis melakukan penelitian ini adalah:

1. Untuk mengetahui mekanisme akad Mudharabah pada Pemberian Modal pakan ikan di PD.Bangun Jaya Fish Farm.

2. Untuk mengetahui perspektif ekonomi syari'ah terhadap Pemberian Modal Pakan Ikan di PD. Bangun Jaya Fish Farm.

\section{Metodologi Penelitian}

Metode yang digunakan dalam penelitian ini adalah Metode deskriptif kualitatif yaitu penelitian yang menggambarkan serta menyajikan suatu peristiwa yang terjadi di lapangan dengan menggunakan teknik pengumpulan tringulasi data yaitu melalui observasi, wawancara, dokumentasi, dan juga penelitian kepustakaan dengan membaca buku, jurnal, artikel, website yang berkaitan dengan masalah yang akan diteliti. ${ }^{6}$

5 M. Ali Hasan, Berbagai Macam Transaksi dalam Islam (Fiqh Muamalat), Jakarta : PT Raja Grafindo Persada, 2003, 169

6 Ida Bagoes Mantra, Filsafat Penelitian dan Metode Penelitian Sosial, Yogyakarta, 2004, 20.
Penelitian deskriptif merupakan penelitian yang berusaha mendeskripsikan sesuatu. Peneliti akan mencari tahu bagaimana Penerapan akad mudharabah pada pemberian modal pakan ikan di PD. Bangun Jaya Fish Farm Desa Cijambe Kecamatan Cijambe Kabupaten Subang. Bagaimana tinjauan ekonomi syari'ah pada pemberian modal pakan ikan di PD. Bangun Jaya Fish Farm-Subang. ${ }^{7}$

Penelitian yang penulis gunakan menurut tiga studi kasus yang dijelaskan oleh Robert K Yin yaitu penelitian eksplanasi. Karena penelitian eksplanasi dimaksudkan agar peneliti lebih mengetahui dan mengembangkan konsep sesuai dengan keadaan di lapangan. Penelitian ini tidak harus dilakukan oleh orang yang sudah mahir dalam masalah yang diteliti tersebut. Orang atau masyarakat sering tidak puas hanya sekedar mengetahui apa yang terjadi, bagaimana terjadinya, tetapi juga ingin tahu mengapa hal tersebut bisa terjadi. Oleh sebab itu penulis bertujuan untuk mengkonfirmasi sebab terjadinya suatu masalah. ${ }^{8}$

Data primer merupakan data yang diperoleh secara langsung oleh penulis dari responden terpilih pada lokasi penelitian. Data primer diperoleh dengan cara wawancara. Pada tanggal 25 September 2019 penulis mendatangi Manajer PD. Bangun Jaya Fish Farm dan pembudidaya ikan di kampung Cibacang Desa Cijambe, berbagai pertanyaan yang penulis tanyakan seperti : ${ }^{9}$

Bagaimana pelaksanaan pemberian modal pakan ikan di PD. Bangun Jaya Fish Farm, bagaimana syarat menjadi mitra PD. Bangun Jaya Fish Farm, bagaimana prosedur dalam bermitra dengan PD. Bangun Jaya Fish Farm, apa saja keuntungan yang diperoleh PD. Bangun Jaya Fish Farm dan pembudidaya dalam pemberian modal pakan ikan, tindakan apa yang dilakukan perusahaan jika pembudidaya melakukan pelanggaran, bagaimana pembagian bagi hasil yang dilakukan, berapa pembagian bagi hasil yang didapatkan pembudidaya dan perusahaan, apa yang menjadi tujuan perusahaan dalam menjalankan kerjasama ini, bagaimana minat calon mitra dalam kerjasama ini, Apa saja manfaat yang di dapatkan oleh kedua belah pihak.

\footnotetext{
7 Suharsimi Arikunto, Prosedur Penelitian,(Jakarta: PT Asdi Mahasatya, 2013), 19

8 Robert K. Yin, Studi Kasus: Desain \& Metode cetakan ke-15, Depok: RajaGrafindo Perkasa,2018. 105.

${ }^{9}$ Wawancara pada tanggal 19 Mei 2019 dengan bapak selaku Pengelola.
} 


\section{EKSISBANK Vol. 3 No. 2 Desember 2019}

Adapun data sekunder merupakan data yang diperoleh dari jurnal, skripsi, situs internet, serta bacaan lain yang berhubungan dengan penelitian yang digunakan sebagai data penunjang. ${ }^{10}$

Adapun teknik pengumpulan data yaitu yang pertama observasi yaitu dengan melakukan pengamatan langsung terhadap objek yang diteliti, Kemudian wawancara merupakan pertemuan dua orang untuk bertukar informasi melalui tanya jawab dengan mengajukan pertanyaan yaitu pengumpulan data yang dilakukan dengan cara memberikan daftar pertanyaan kepada perusahaan PD. Bangun Jaya Fish Farm dan pembudidaya ikan, serta tokoh masyarakat yang mengetahui dan faham mengenai pemberian modal pakan ikan.

Setelah mendapatkan data kemudian menggunakan tringulasi data yaitu tenik pemeriksaan keabsahan data dengan mencari tahu sesuatu hal yang lain diluar data yang ada untuk keperluan pengecekan atau sebagai pembanding. Teknik tringulasi ini digunakan sebagai pemeriksaan melalui sumber lain. Dengan dilengkapi penelitian yang dilakukan dengan cara pengumpulan data, melalui bahanbahan kepustakaan berupa tulisan-tulisan ilmiah, jurnal, laporan penelitian, buku-buku, dan sumber lain seperti internet dan surat kabar yang berhubungan dengan topik yang diteliti.

Kemudian penulis melakukan analisis data merupakan upaya untuk mencari secara sistematis hasil observasi, wawancara untuk meningkatkan pemahaman penelitian tentang kasus yang diteliti.

\section{HASIL DAN PEMBahasan}

Hasil dari analisis data yang dilakukan, Pakan ikan menjadi kebutuhan utama dalam bisnis ikan air tawar, pakan ikan yang menjadi makanan sehari-hari ikan air tawar di perusahaan kolam air deras yang bertempat di Desa Cijambe, Kecamatan Cijambe, Kabupaten Subang, tepatnya di kampung Sukajaya RT/RW 11/04 Desa Cijambe. Jenis-jenis ikan yang dibudidayakan beragam mulai dari ikan nila merah, ikan nila hitam dan ikan mas, ketiga ikan ini yang lebih populer dibudidayakan oleh para

10 M. Djuanidi dan Fauzan Almansyu, Metode Penelitian Kualitatif, Jogjakarta, 2013, hlm165. pengusaha ikan kolam air deras. Adapun pelaksanaan pemberian modal pakan ikan di PD. Bangun Jaya Fish Farm Desa Cijambe-Subang yaitu:

a. Perjanjian Pemberian Modal Pakan Ikan Perjanjian kerjasama usaha dilakukan di kantor PD. Bangun Jaya Fish Farm yang berada di Saung Kolam Ar-Rossa kampung Sukajaya. Dalam perjanjian tersebut para calon mitra selain harus membawa persyaratan diatas juga harus menjual ikannya kepada perusahaan PD. Bangun Jaya Fish Farm, pembagian bagi hasil dibagi sesuai kesepakatan bersama. Pembagian bagi hasil dihitung setelah ikan habis dipanen dan pembagian bagi hasil antara kedua belah pihak masing-masing mendapatkan 40\%-60\%, dimana pengelola mendapatkan $40 \%$ dan perusahaan mendapatkan $60 \%$ dari hasil panen setelah dipotong modal pakan dan benih ikan. Apabila pengelola melakukan sesuatu diluar ketentuan atau kesepakatan maka perusahaan akan memberikan sanksi yang sesuai.

b. Pemberian Modal Pakan Ikan

PD. Bangun Jaya Fish Farm tahu betul apa yang pembudidaya rasakan dalam usaha ikan kolam air deras bahwa pakan ikan menjadi keluhan utama para pembudidaya. PD. Bangun Jaya Fish Farm mencoba memberikan solusi untuk perkembangan usahanya, yang awalnya tidak produktif dalam usahanya menjadi lebih baik lagi (produktif). Dasar dari pemberian modal pakan ikan ini adalah unsur tolong menolong dan saling percaya diantara kedua pihak yang melakukan perjanjian kerjasama.

c. Kerjasama Pemberian Modal Pakan Ikan

Penyebab dilakukannya kerjasama pemberian modal pakan ikan Menurut Pak Djoko sebagai manajer di PD. Bangun Jaya Fish Farm , seleksi orang-orang yang dapat dipercaya hal yang utama, orang tersebut yang sudah kenal baik dengan saya, tidak banyak macam-macam dalam artian bisa diajak berbisnis dengan prosedur yang telah ditetapkan, maka dia akan masuk kriteria. Dan saya melakukan kerjasama ini untuk membantu pembudidaya-pembudidaya supaya lebih produktif lagi dalam usahanya. Selain itu menurut Bapak Dadang, selaku pembudidaya ikan air tawar faktor yang 
EKSISBANK Vol. 3 No. 2 Desember 2019

menyebabkan gabung dalam kerjasama dengan PD. Bangun Jaya Fish Farm adalah untuk mengurangi pengeluaran harian pembelian pakan sebab banyak pengeluaran dalam keluarga saya.

Dari beberapa penjelasan diatas bisa dipahami bahwa faktor yang menyebabkan terjadinya kerjasama pemberian modal pakan ikan di PD. Bangun Jaya Fish Farm Kampung Sukajaya Desa Cijambe Kecamatan Cijambe Kabupaten Subang ini adalah karena keterbatasan modal yang cukup besar dalam melakukan usaha budidaya ikan air tawar.

Syarat dan rukun dalam akad Mudharabah juga harus terpenuhi karena jika tidak maka tidak sahnya akad tersebut, agar akad tersebut sah maka harus sesuai dengan rukun dan syaratnya. Hal ini berdasarkan Fatwa Dewan Syari'ah Nasional Majelis Ulama Indonesia nomor 115/DSN-MUI/IX/2017 tentang akad mudharabah.

Berdasarkan pemaparan diatas bahwa kerjasama yang dilakukan pembudidaya di kampung Sukajaya Desa Cijambe Kecamatan Cijambe Kabupaten Subang, telah memenuhi rukun dan syarat yang telah dianjurkan dalam Islam.

\section{IV.KESIMPULAN}

Setelah penulis mendeskripsikan mengenai mekanisme pemberian modal pakan ikan di Kampung Sukajaya Desa Cijambe Kecamatan Cijambe Kabupaten Subang, sebagaimana telah dijelaskan pada bab-bab sebelumnya maka penulis menarik kesimpulan dalam skripsi ini sebagai berikut.

Akad mudharabah pada pemberian modal pakan ikan merupakan bentuk kerjasama yang dilakukan oleh salah satu perusahaan dagang dengan seorang pembudidaya yang mempunyai skill dalam mengelola ikan. Mekanisme yang dilakukan dalam pemberian modal pakan ikan ini adalah PD. Bangun Jaya Fish Farm melakukan perjanjian lisan dengan calon pengelola usahanya (pembudidaya) untuk mengembangkan usahanya. Kemudian proses pemberian modal pakan berlangsung mulai dari penanaman benih ikan sampai pemanenan ikan dengan lama usaha selama 4 bulan. Pembagian nisbah keuntungan setelah semua dari hasil panen tersebut dikurangi modal pakan dan laba tersebut dibagi dua yakni $60 \%$ (shahibul maal) dan 40\% (mudharib).
Masalah dari penjualan ikan kepada pihak lain itu dikarenakan oknum pembudidaya yang serakah dan tidak mengikuti dan mentaati dan ingkar atas apa yang telah disepakati sebelumnya.

Tinjauan Ekonomi Syariah pada pemberian modal pakan ikan, jika ditinjau dari akad mudharabah secara umum berdasarkan Fatwa Dewan Syari'ah Nasional Nomor 115/DSNMUI/IX/2017 tentang akad mudharabah. Pemberian modal pakan ikan ini sah atau boleh dilakukan, karena dalam perjanjian ini sesuai dengan Rukun dan Syaratnya juga ketentuan akad mudharabah dimana pembagian bagi hasil dan modal yang telah diketahui dan telah sesuai dengan ketentuan syariat Islam.

\section{DAFTAR Pustaka}

[1] Afrianto dan Liviawaty, "Jurnal Vita Yanuar", (Universitas Antakusuma, 2017).

[2] Hasil wawancara, Bapak Aep, Pembubidaya ikan kolam air deras, pada tanggal 03 Agustus 2019.

[3] Hasil wawancara, Bapak Aep, Pembubidaya ikan kolam air deras, pada tanggal 03 Agustus 2019

[4] Hasil wawancara, Bapak Aep, Pembubidaya ikan kolam air deras, pada tanggal 03 Agustus 2019.

[5] Ida Bagoes Mantra, "Filsafat Penelitian dan Metode Penelitian Sosia"l, Yogyakarta, 2004.

[6] M. Ali Hasan, "Berbagai Macam Transaksi dalam Islam" (Fiqh Muamalat), Jakarta : PT Raja Grafindo Persada, 2003.

[7] M. Ali Hasan, "Berbagai Macam Transaksi dalam Islam" (Fiqh Muamalat), Jakarta : PT Raja Grafindo Persada, 2003.

[8] Robert K. Yin, Studi Kasus: Desain \& Metode, cetakan ke-15, Depok: RajaGrafindo Perkasa,2018.

[9] Suharsimi Arikunto, "Prosedur Penelitian",(Jakarta: PT Asdi Mahasatya, 2013.

[10] Syarafuddin dkk, "Studi Islam 2", Surakarta: Lembaga Pengembangan IlmuIlmu Dasar Bidang Studi Islam dan Kemuhammadiyahan UMS, 2006. 